๑ Д. С. Гриценко, к.т.н., ст. викладач, НТУУ «КПІ», Київ, Україна

\title{
КОМП'ЮТЕРНЕ МОДЕЛЮВАННЯ КУЛАЧКОВОГО МЕХАНІЗМУ ПРИВОДУ ПОВОРОТНОГО СТОЛУ ТАМПОДРУКАРСЬКОЇ МАШИНИ
}

У статті проведено моделювання засобами комп'ютерного середовища Autodesk Inventor з метою підтвердження проведених аналітичних досліджень параметрів кулачкового механізму приводу поворотного столу подавання виробів у зону друку тамподрукарської машини, який перетворює обертальний рух постійної швидкості у періодичний обертальний рух, який описується диференціальним законом.

Ключові слова: комп'ютерне моделювання; тамподрукарська машина; друкування; поворотний стіл; кулачковий механізм; закон періодичного руху; швидкість.

\section{Постановка проблеми}

Кулачковий механізм періодичного повороту доцільно використовувати для здійснення періодичного поворотного руху транспортувального пристрою подавання виробів у зону друку тамподрукарської машини [1]. До таких транспортувальних пристроїв ставляться вимоги точної фіксації виробів у зоні друку, можливості задання необхідного закону періодичного руху та будь-якого співвідношення періоду вистою до повного кінематичного циклу за вимогами технологічного процесу.

Одним із методів підтвердження достовірності проведених аналітичних розрахунків запропонованих механізмів приводу [2] для широкого впровадження їх у механізмах приводу ланок машин, які здійснюють періодичний рух, є використання засобів комп'ютерного моделювання. Такі дослідження дозволяють спростити і пришвидшити процес синтезу кулачкового механізму приводу, зменшує вірогідність появи похибок і дозволяє оптимізувати конструктивні параметри.

\section{Аналіз попередніх}

\section{досліджень}

На сьогодні у літературних джерелах не представлено результатів аналітичних досліджень кулачкових механізмів періодичного повороту із профілем, виконаним із розривом по мінімальних радіусах-векторах. Наведена в джерелах [3-5] методика розрахунку не дозволяє провести розрахунки механізмів такого типу. 


\section{МАШИНИ І АВТОМАТИЗОВАНІ КОМПЛЕКСИ}

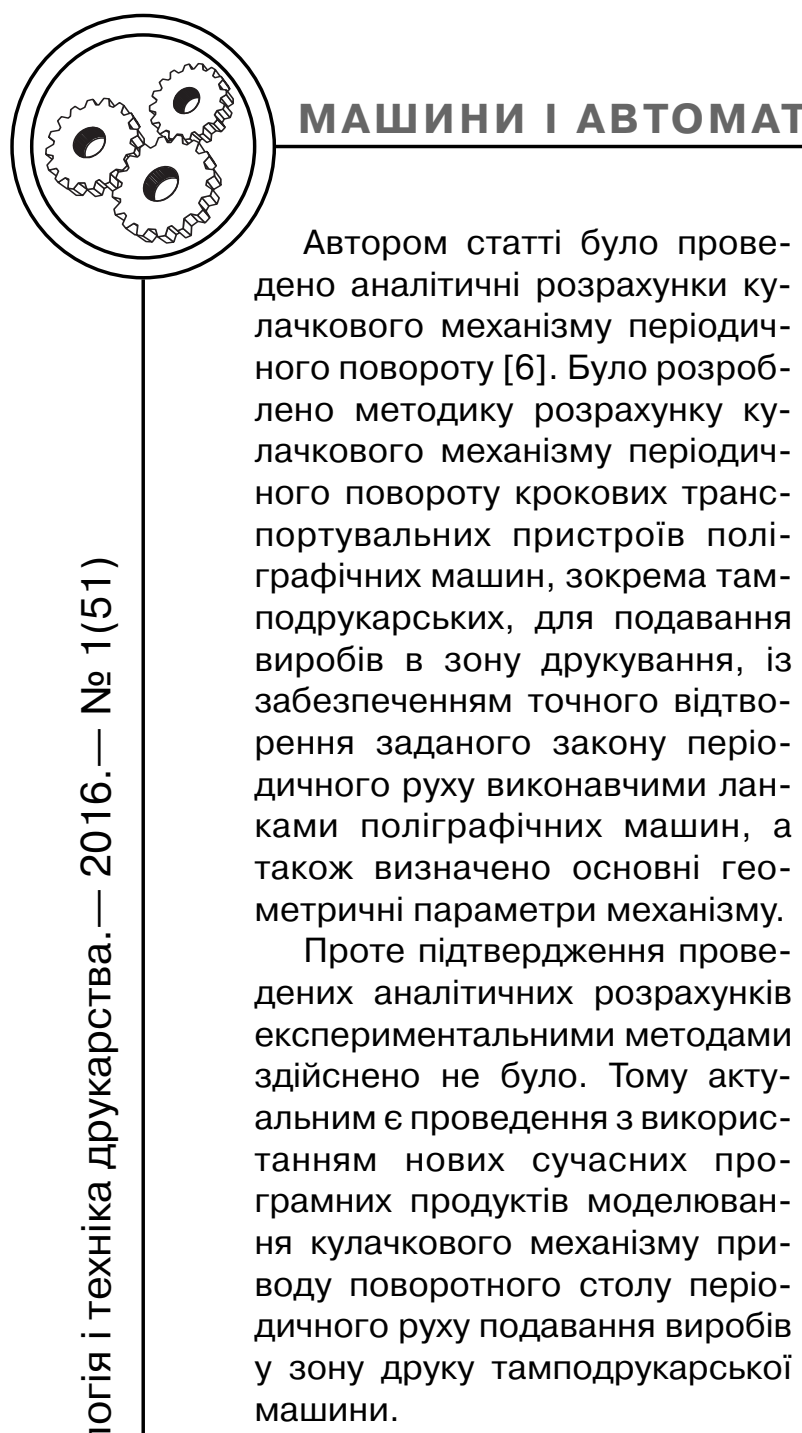

\section{Мета роботи}

Метою роботи є перевірка результатів проведених аналітичних досліджень кулачкового механізму приводу поворотного столу періодичного руху подавання виробів у зону друку тамподрукарської машини з використанням засобів комп'ютерного моделювання.

\section{Результати проведених досліджень}

Вибір системи моделювання. Одним із сучасних методів проведення експериментальних досліджень є комп'ютерне моделювання. Комп'ютерне сере- довище Autodesk Inventor широко використовується інженерами та науковцями для проектування, візуалізації і виконання всебічного аналізу цифрових моделей виробів. Функції програми допомагають уникнути проектних помилок, більш ефективно співпрацювати і швидше виводити на ринок інноваційні вироби. Модель, створена в такому програмному середовищі, $є$ точним цифровим 3D-прототипом, який надає всі можливості для перевірки відповідності розробленої продукції функціональним та дизайнерським вимогам, перевірки поведінки виробів при експлуатації в цифровому форматі, тим самим мінімізуючи необхідність створення фізичних дослідних зразків. Inventor включає в себе прості у використанні і тісно взаємодіючі між собою засоби динамічного аналізу і розрахунку напруження, які допомагають досліджувати поведінку деталей та виробів в умовах реальної експлуатації та швидко випускати на ринок високоякісну продукцію [7].

За допомогою такої комп'ютерної програми створено цифрові моделі механізмів, що дає можливість виконати перевірку взаємодії ланок механізмів та забезпечення заданого закону періодичного руху веденої ланки.

Достовірність отриманих даних $є$ підтвердженою у випадку співпадіння заданого закону періодичного руху в початкових параметрах під час розрахунку і отриманого (виміряного) після виготовлення механізму періодичного повороту. Для дослід- 
ження кутової швидкості веденої ланки механізму періодичного повороту використано модуль динамічного моделювання Simulation програми автоматичного проектування Autodesk Inventor.

Для досягнення мети дослідження вирішувались наступні задачі:

- проектування відповідного механізму періодичного повороту відповідно до розрахунків програми;

- дослідження закону періодичного руху відповідного спроектованого механізму періодичного повороту веденої ланки та співставлення із заданими значеннями;

- отримання даних, які уточнюють проведені дослідження.

Комп'ютерне моделювання кулачкового механізму. Для початку роботи вибрано основні параметри механізму, рекомен- дації щодо вибору яких наведені у попередніх дослідженнях [6]. За допомогою запропонованої програми [8], ввівши початкові параметри розрахунку, отримуємо результат обчислення у графічному вигляді та у вигляді табличних даних, які відображають розміри радіусів-векторів змінного профілю кулачка та відповідні біжучі кути повороту. Далі, використовуючи розраховані дані, у програмі Autodesk Inventor побудовано профіль кулачка (рис. 1) та створено сам тривимірний кулачок.

За наведеними у програмі даними побудовано інші елементи механізму: основу, циліндричну зубчасту передачу, колесо якої виконує роль коромислового диску, ролики, ведений вал. Для навантаження механізму створимо ведену ланку у вигляді поворотного столу тамподрукарської машини з чотирма позиціями для кріплення виробів (рис. 2).

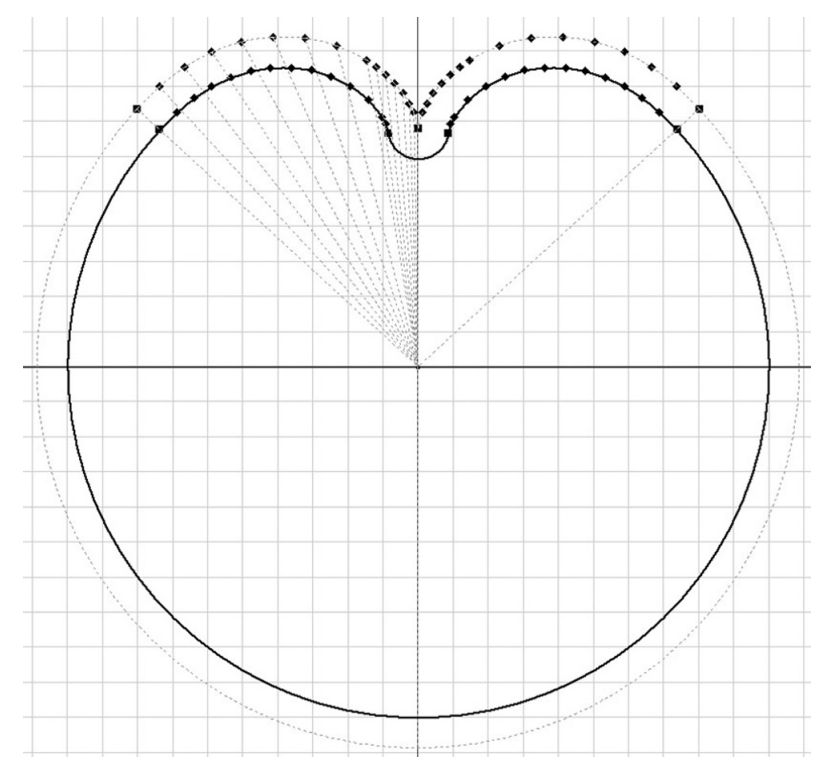

Рис. 1. Профіль кулачка, побудований у програмі Autodesk Inventor 


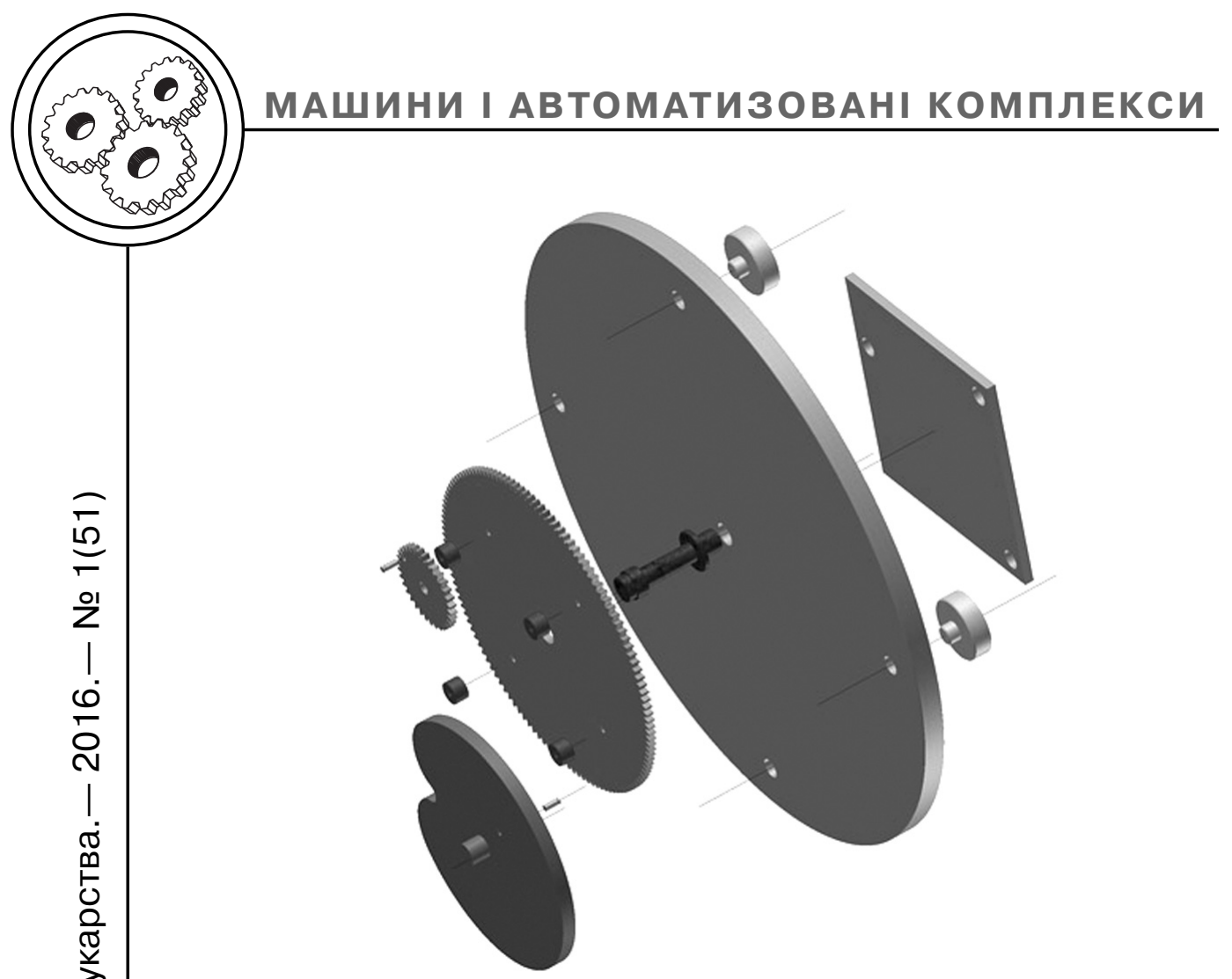

Рис. 2. Деталі механізму періодичного поворотного руху у програмі Autodesk Inventor

Далі створено зборку кулач- метрів столу проведено розракового механізму з накладанням необхідних зв'язків на ланки (рис. 3). хунки з використанням таких даних: закон періодичного руху «2.12», базовідстань - b $=300$ мм, фазовий кут $-\varphi=160$ град., Дослідження роботи кулач- радіус коромислового диску кового механізму на ПК. I= 164 мм, частота обертання гоВідповідно до силових пара- ловного валу $-\mathrm{n}=20$ об/хв.

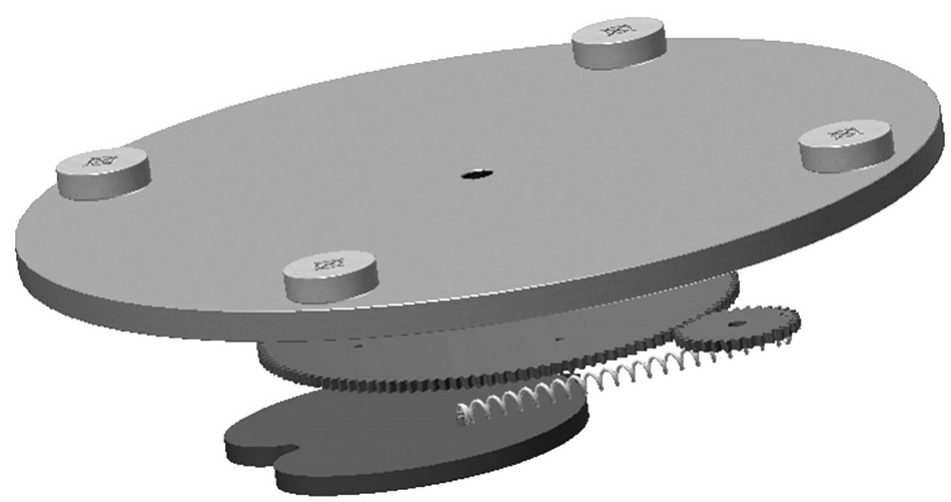

Рис. 3. Спроектований чотирипозиційний поворотний стіл тамподрукарської машин 
В середовищі Simulation (динамічне моделювання) підпрограми Autodesk Inventor на відповідні вузли накладено сили тертя, на кулачок постійний обертальний момент відповідний частоті обертання 20 об/хв., пружний зв'язок між кулачком і шестернею зубчастої передачі та силу земного тяжіння. Для того, щоб ланки механізму впливали одна на одну як тверді тіла, накладено на них «2D-контакт». Це дозволяє отримати змодельовані, наближені до реальних, необхідні параметри досліджуваного механізму.

У вікні симулятору руху встановлено параметри: час моделювання -6 с, оскільки відповідно заданій швидкості обертання кулачка один період руху коромислового диску дорівнюе 3 с, у полі «Фільтр» відтворювати кожний кадр.

Після закінчення обраховування у програмі за допомогою вікна «пристрій графічного виводу» можливо переглянути різноманітні результати моделювання, необхідні для характеристики роботи механізму. У нашому випадку вибрано параметр «Швидкість» веденої ланки і отримано діаграму кутового переміщення.

За допомогою середовища математичного моделювання MathCAD [9] проведено обробку отриманих значень і порівняно зі значеннями відповідно яких проводились розрахунки. Графіки значень швидкостей розрахованих і змодельованих представлені на рис. 4 в інваріантній формі. Суцільною лінією представлено заданий закон періодичного руху «2.12», а пунктирною - отримані значення швидкості обертання. Отримані значення вираховувались за формулою:

$$
b_{k}=\omega_{k} \frac{30 \cdot \varphi}{\pi \cdot n \cdot \gamma_{\Sigma}}
$$

де $\omega_{k}$ - кутова швидкість кулачка, $\varphi$ - фазовий кут, $\mathrm{n}$ - частота

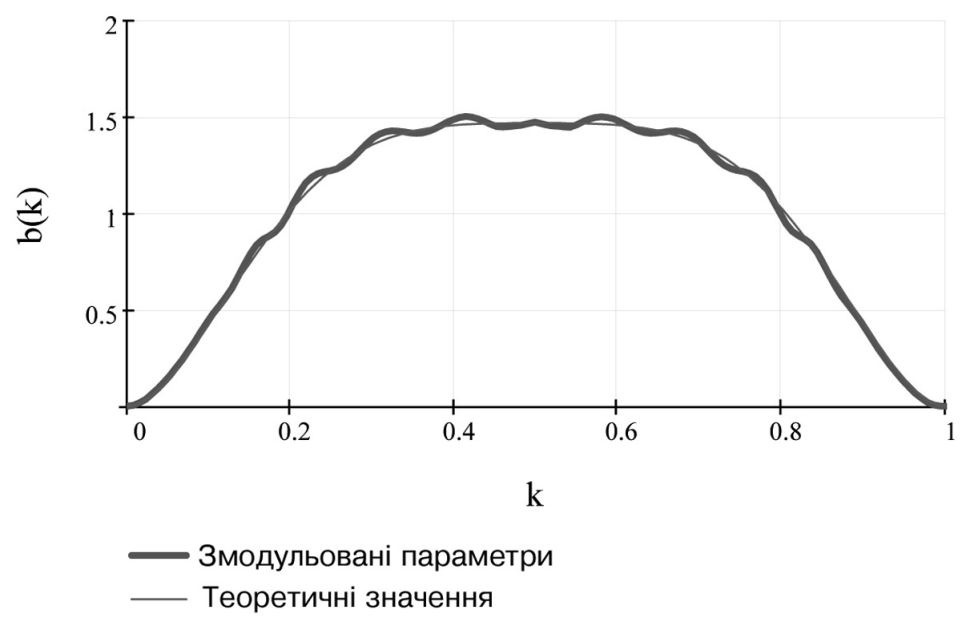

Рис. 4. Порівняння розрахованих і змодельованих значень швидкостей 


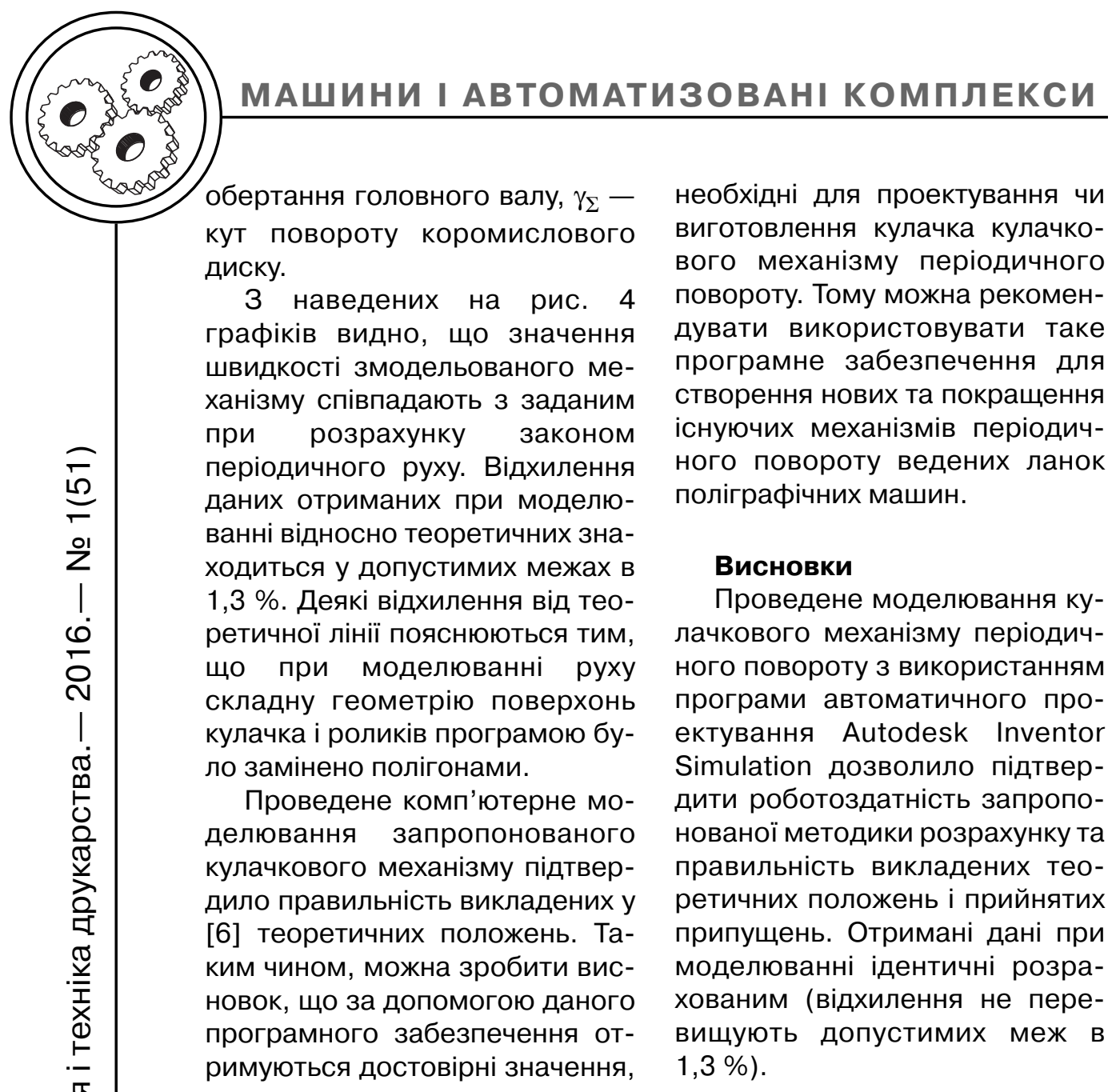

\section{Список використаної літератури}

1. Петрук А. І. Визначення раціональної структури механізмів періодичного повороту поліграфічних машин / А. І. Петрук, Д. С. Гриценко // Збірник наукових праць «Технологія і техніка друкарства». - К., 2007. - № 3-4. C. 86-94. - Режим доступу : http://druk.kpi.ua/publications/view_publications/authors/\%D0\%9F\%D0\%B5\%D1\%82\%D1\%80\%D1\%83\%D0\%BA.

2. Пат. 32250 України, МПК (2006) F 16 Н 25/00. Пристрій для періодичного обертального руху веденої ланки / А. І. Петрук, Д. С. Гриценко, О. Я. Моргун. - № u200714825; заявл. 26.12.2007; опубл. 12.05.2008, Бюл. № 9. $-3 \mathrm{c}$.

3. Тир К. В. Комплексный расчет кулачковых механизмов / К. В. Тир. М. : Машгиз, 1958. - 308 с.

4. Артоболевский И. И. Теория механизмов и машин : учебник [для студ. высш. учеб. зав.] / И. И. Артоболевский. - М. : Наука, 1988. - 640 с.

5. Кожевников С. Н. Теория механизмов и машин : учебник [для студ. высш. учеб. зав.] / С. Н. Кожевников. - М. : Машиностроение, 1973. $591 \mathrm{c}$.

6. Шостачук Ю. О. Розрахунок кулачкового механізму періодичного повороту / Ю. О. Шостачук, Д. С. Гриценко // Збірник наукових праць «Технологія і техніка друкарства». - К., 2012. - № 1(35). - С. 97-106. Режим доступу : http://ttdruk.vpi.kpi.ua/article/view/32748. 
7. Концевич В. Г. Твердотельное моделирование машиностроительных изделий в Autodesk Inventor / В. Г. Концевич. - К.-М. : ДиаСофтЮП, ДМК Пресс, 2007. - 672 c.

8. Свідоцтво, про реєстрацію авторського права на твір № 47250, Україна. Розрахунок кулачкового механізму періодичного повороту (комп'ютерна програма) / Ю. О. Шостачук, Д. С. Гриценко. - Заяв. № 47533 від 16.11.2012; опубл. 16.01.2013.

9. Кирьянов Д. В. Самоучитель Mathcad 13 / Д. В. Кирьянов. - СПб. : БХВ-Петербург, 2006. - 528 с.

\section{References}

1. Petruk A. I. Vyznachennia ratsionalnoi struktury mekhanizmiv periodychnoho povorotu polihrafichnykh mashyn / A. I. Petruk, D. S. Hrytsenko // Zbirnyk naukovykh prats «Tekhnolohiia i tekhnika drukarstva». - K., 2007. - № 3-4. S. 86-94. - Rezhym dostupu : http://druk.kpi.ua/publications/view_publications/authors/\%D0\%9F\%D0\%B5\%D1\%82\%D1\%80\%D1\%83\%D0\%BA.

2. Pat. 32250 Ukrainy, MPK (2006) F 16 H 25/00. Prystrii dlia periodychnoho obertalnoho rukhu vedenoi lanky / A. I. Petruk, D. S. Hrytsenko, O. la. Morhun. — № u200714825; zaiavl. 26.12.2007; opubl. 12.05.2008, Biul. № 9. - 3 s.

3. Tir K. V. Kompleksnyj raschet kulachkovyh mehanizmov / K. V. Tir. - M. : Mashgiz, 1958. - $308 \mathrm{~s}$.

4. Artobolevskij I. I. Teorija mehanizmov i mashin : uchebnik [dlja stud. vyssh. ucheb. zav.] / I. I. Artobolevskij. - M. : Nauka, 1988. - $640 \mathrm{~s}$.

5. Kozhevnikov S. N. Teorija mehanizmov i mashin : uchebnik [dlja stud. vyssh. ucheb. zav.] / S. N. Kozhevnikov. - M. : Mashinostroenie, 1973. - $591 \mathrm{~s}$.

6. Shostachuk lu. O. Rozrakhunok kulachkovoho mekhanizmu periodychnoho povorotu / lu. O. Shostachuk, D. S. Hrytsenko // Zbirnyk naukovykh prats «Tekhnolohiia i tekhnika drukarstva». - K., 2012. - № 1(35). - S. 97-106. Rezhym dostupu : http://ttdruk.vpi.kpi.ua/article/view/32748.

7. Koncevich V. G. Tverdotel'noe modelirovanie mashinostroitel'nyh izdelij v Autodesk Inventor / V. G. Koncevich. - K.-M. : DiaSoftJuP, DMK Press, 2007. 672 s.

8. Svidotstvo, pro reiestratsiiu avtorskoho prava na tvir № 47250, Ukraina. Rozrakhunok kulachkovoho mekhanizmu periodychnoho povorotu (komp'iuterna prohrama) / lu. O. Shostachuk, D. S. Hrytsenko. - Zaiav. № 47533 vid 16.11.2012; opubl. 16.01.2013.

9. Kir'janov D. V. Samouchitel' Mathcad 13 / D. V. Kir'janov. - SPb. : BHVPeterburg, 2006. $-528 \mathrm{~s}$.

\section{В статье осуществлено моделирование средствами компьютерной среды Autodesk Inventor с целью подтверждения проведенных аналитических исследований параметров кулачкового механизма привода поворотного стола подачи изделий в зону печати тампопечатной машины, который преобразует вращательное движение постоянной скорости в периодическое вращательное движение, которое описывается дифференциальным законом.}

Ключевые слова: компьютерное моделирование; тампопечатная машина; печать; поворотный стол; кулачковый механизм; закон периодического движения; скорость. 
The article presents the modeling with the computer simulation environment Autodesk Inventor to confirm the feasibility studies of the parameters of cam drive mechanism of a rotary table for products delivery to the printing area a screen printing press that converts the rotational motion of constant velocity in periodic rotational motion, which is described by the differential law.

Keywords: computer modeling; screen printing press; printing; rotary table; cam mechanism; the law of periodic motion; velocity.

Рецензент - Ю. О. Шостачук, к.т.н., доцент, НТУУ «КП।»

Надійшла до редакції 22.12.15 